\title{
Information Literacy and Changes within Higher Education
}

\author{
Eystein Gullbekk1, Therese Skagen ${ }^{2}$, Anne Sissel Vedvik Tonning2, Maria Carme Torras ${ }^{2}$ \\ University of Oslo ${ }^{1}$, University of Bergen ${ }^{2}$
}

Contact:

E-mail: post@noril.uib.no

\section{EDITORIAL}

Libraries have always been closely linked with educational institutions. The role of higher education libraries in particular has been to provide access to academically relevant literature that will serve as the basis for university teaching.

In their encounters with researchers and students, librarians have always had a pedagogical role in giving adequate guidance and courses to library users. Crucially, librarians have the necessary overview of classification systems and the hierarchical orders of organisation needed in order to store and retrieve materials within the relevant collections.

A constant of society, however, is change. The societal contexts in which libraries find themselves are far from fixed. Higher education libraries today are faced with new forms of interaction with increasingly internationalised educational policies and systems of higher education undergoing rapid change, not least due to the emergence of global information networks and the far-reaching effects of such developments upon all academic subject areas. All this cannot but influence the role of the library and its pedagogical mission.

In the first place, educational policies are rapidly changing. From a European perspective, new strategies in this field are becoming increasingly influential through the Bologna process and the various national initiatives undertaken in its wake. One may note here the emphasis on contractual agreements between students and educational institutions. This goes together with a demand for clear and specific communication as to the learning outcomes that students, and society generally, should expect from any given course of study. At a more regional level, the latest educational reforms in the Nordic countries call for a wider variety of pedagogical methods to facilitate learning in diverse contexts. The reform documents generally emphasise the need for cooperation across disciplinary and vocational boundaries within society: they then go on to demand collaborative learning models within the higher education sector that are designed to meet those needs. The Bologna process, again, also emphasised the importance of facilitating life-long learning. This concept is no less central to the Alexandria

Nordic Journal of Information Literacy in Higher Education, 2009. (C2009 Eystein Gullbekk, Therese Skagen, Anne Sissel Vedvik Tonning, Maria Carme Torras 
proclamation, where information literacy is another crucial keyword. Information literacy is here regarded as fundamental to citizens' access to life-long learning, thus linking libraries and educational institutions in the closest possible fashion.

In the second place, recent research has reinvigorated the idea of active learning. Learning is a process which takes place at the intersection points between a number of contexts. Human beings are constantly interpreting the knowledge they acquire. Sociological, psychological, ethnographic and pedagogical studies of information literacy describe learning as a process where knowledge and skills developed within one area are renegotiated and transformed through the encounter with other areas. In the seventies the concept of 'information skills' was used to examine how people acquire information through the use of relevant sources and technologies. During the last decades these skills have been incorporated into the much wider concept of 'information literacy'. Today information literacy is widely understood to concern 'knowing when and why you need information, where to find it and how to evaluate, use and communicate it in an ethical manner' (CILIP).

The concept of information literacy, then, has traditionally referred to generic skills. However, information literacy is also to some degree context-bound. Knowledge is in fact organised differently within different subject areas, not least since practical approaches to learning can differ widely between disciplines. Central problems are formulated differently, rules that govern the use of supporting evidence and its relation to conclusions may vary, subject databases for searching literature and materials rarely correspond across disciplines, and conventions as to what needs citation and how often differ as well. Furthermore, information literacy develops through specific social networks, and is thus legitimated through multiple relations of trust. NORIL will examine how the library facilitates learning within the context of the various arenas and communities in which students and researchers necessarily participate.

In the third place, the material and technological conditions surrounding libraries and educational institutions have undergone rapid changes. The organisation of information and the transaction and preservation of knowledge is constantly being expanded and restructured. The information sources provided by higher education libraries exist within the context of a complex electronically accessible global information network. Students and researchers thus encounter libraries and their services very differently today than they did mere decades ago. Today everyone is increasingly forced to navigate an online network where decisions continuously need to be made. This network will not cease to expand, as the recent emphasis on open access information sharing through web 2.0 and social networking websites clearly demonstrates.

The library as a pedagogical institution needs to cope with these developments as they are happening, and clarifying the links between them thus becomes a crucial task. As the future centres of competence for information navigation within higher education, libraries need to establish research-based pedagogical approaches which can integrate knowledge from different subject areas as well as knowledge about the workings of the various disciplines themselves.

The many practical projects seeking to implement new teaching models within university libraries have led to a number of publications. However, these have largely been simple descriptions of various such models, which too often lack a background in systematic research projects or solidly based visions of learning and knowledge. During the last decade or so there has been a new emphasis on anchoring practice in research and theory, and one aim of NORIL is to contribute to this trend.

This first issue of NORIL contains three peer-reviewed articles which all focus in different ways on central aspects of information literacy within higher education. We also print an interview with Carol C. Kuhlthau about her view of the roles of the library and librarians within an information society. 
Based on a discussion of a set of data about participants in a group-based assignment, and on a critique of the individualistic premises of Kuhlthau's ISP-model, Jette Hyldegård argues that points of uncertainty in information seeking may be interpreted differently according to whether those interpretations are carried out individually or within the group. Such uncertainty is part and parcel of the process of generating new knowledge through group cooperation. At a group level, uncertainty is dealt with partly by negotiating a shared knowledge base, encompassing a shared focus and shared aims. Hyldegård's argument encourages renewed reflection upon the complexity of information seeking in an academic context, as well upon the learning benefits which may ensue when information searching is connected with group assignments.

Sharon Markless argues for a new conception of information literacy for the digital learning environment in higher education. She challenges a number of information literacy frameworks currently used in higher education and puts forward a new framework to encourage critical reflection on current theory and practice. A key feature of her framework, previously disregarded, is the influence of both discipline context and the digital environment on information behaviour.

Susanne Mikki's contribution concerns the use of citation databases as central elements of information literacy courses. Knowledge of the workings of different search engines often decides the content of courses provided by information literacy specialists. Mikki has investigated two of the most frequently used citation databases among students and researchers: Web of Science and Google Scholar. Her comparative exercise shows how exactly research is retrieved via the specific impact and content of these databases.

Launching a new Open Access journal involves many stages and learning processes. But after a couple of postponements, NORIL is finally online! The Editors are grateful to the Editorial Board and their network for their thorough referee-work. We hope you will enjoy this first issue of NORIL. 